BANCA D'ITALIA

E U R O S I S T E M A

Questioni di Economia e Finanza

(Occasional Papers)

The macroeconomic impact of Basel III on the Italian economy

by Alberto Locarno 

13 BANCA D'ITALIA

E U ROS I S T E MA

\section{Questioni di Economia e Finanza}

(Occasional papers)

The macroeconomic impact of Basel III on the Italian economy

by Alberto Locarno

Number 88 - February 2011 
The series Occasional Papers presents studies and documents on issues pertaining to the institutional tasks of the Bank of Italy and the Eurosystem. The Occasional Papers appear alongside the Working Papers series which are specifically aimed at providing original contributions to economic research.

The Occasional Papers include studies conducted within the Bank of Italy, sometimes in cooperation with the Eurosystem or other institutions. The views expressed in the studies are those of the authors and do not involve the responsibility of the institutions to which they belong.

The series is available online at www.bancaditalia.it. 


\title{
THE MACROECONOMIC IMPACT OF BASEL III ON THE ITALIAN ECONOMY
}

\author{
by Alberto Locarno
}

\begin{abstract}
This paper provides an assessment for the Italian economy of the costs - both during the transition period and in the long run - of the new regulatory standards (the Basel III reform), focusing exclusively on capital and liquidity requirements. The analysis is fully consistent with those of the Macroeconomic Assessment Group (MAG, 2010a,b) and of the Long-term Economic Impact group (BCBS, 2010a). Overall, the economic impact of the new regulation is small. For each percentage point increase in the capital ratio implemented over an eight-year horizon, the level of GDP would decline by $0.00-0.33 \%$, corresponding to a reduction of the annual growth rate of output in the transition period of 0.00-0.04 percentage points. If nonspread effects - i.e. effects due to deleveraging of banks' balance sheets - are also taken into account, the GDP loss would rise to $0.03-0.39 \%$, corresponding to a $0.00-0.05$ percentage point decrease in average annual output growth. The maximum GDP loss occurs around nine years after the beginning of the transition period; thereafter, output slowly recovers and by the end of 2022 it is above the baseline value. Compliance with the new liquidity standards also has a small effect on output. The above estimates suggest that the economic costs of stronger capital and liquidity requirements are small and become negligible if compared with the potential benefits that can be reaped from reducing the frequency of systemic crises and the amplitude of boom-bust cycles.
\end{abstract}

JEL Classification: E44, E61, G21, G38

Keywords: Basel III, Modigliani-Miller theorem, flow/stock costs of equity finance, capital/liquidity requirements.

\footnotetext{
‡ Banca d’Italia, Economic Outlook and Monetary Policy Department, Modelling and Forecasting Division. I am grateful to Paolo Angelini, Michele Caivano and Laura Cerioni, who contributed to all the stages of work on the paper.
} 



\section{Contents}

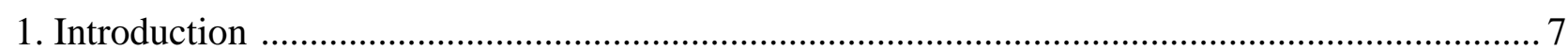

2. Higher capital and liquidity requirements: design of the experiments ..................................... 8

3. From capital and liquidity ratios to interest rate spreads and credit availability ....................... 10

4. The Bank of Italy Quarterly Model and its reduced-scale version ........................................... 12

5. Higher capital and liquidity requirements: transition costs .................................................. 14

6. Higher capital and liquidity requirements: steady-state costs ............................................ 18

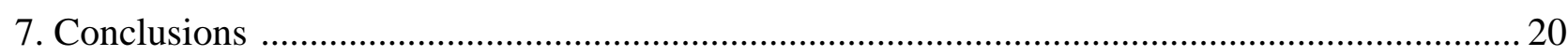

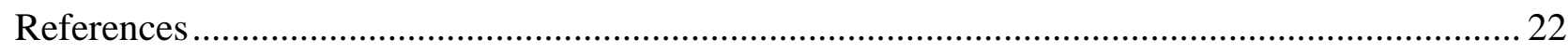

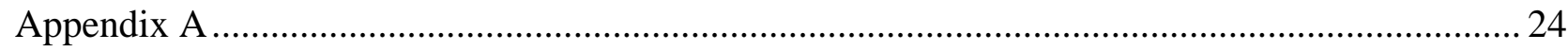

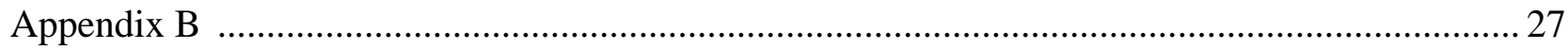





\section{Introduction}

The financial crisis that started in August 2007 has highlighted the huge costs imposed on society by a fragile banking system. A strong and resilient credit sector is the foundation for sustainable economic growth, as banks are at the heart of the financial intermediation process. When an economy-wide shock reduces the net worth of poorly capitalised credit institutions, attempts to cut down financial leverage may translate into asset fire sales and credit crunches, impairing the smooth working of financial markets; the resulting contraction in household and firm spending can generate a fall in economic activity well above the size of typical cyclical downturns, as the 2008-2009 global recession clearly attests.

The recent financial crisis exposed the areas of weakness in the international regulatory framework and revived the debate on banking supervision and macroprudential policies. One of the main reasons the recent crisis became so severe was that banks in many countries had built up excessive on- and off-balance sheet leverage, accompanied by a gradual erosion of the level and quality of the capital base and by inadequate liquidity buffers. The crisis was further amplified by a procyclical deleveraging process and by the interconnectedness of systemic institutions through an array of complex transactions.

Following the recommendations of the Financial Stability Board (FSB) and the Heads of State and Government of the G20 countries, on 12 September 2010 the Governors and Heads of Supervision of the Basel Committee on Banking Supervision (BCBS) made public the details of the new regulatory framework on banks' capital and liquidity, with the goal of promoting a more resilient banking sector. The reinforcement of the prudential regulatory framework concerns the new definition of capital, the introduction of a leverage ratio and the establishment of new liquidity standards. The capital strengthening will be pursued (a) by improving the quality of regulatory capital, in particular by requiring a shift in the composition of bank capital in favour of common equity; (b) by setting higher minimum levels for top quality capital; and (c) by maintaining capital in excess of the minimum requirements, to ensure that banks keep a buffer that can be used to absorb losses during periods of financial and economic stress. The agreement provides for the new rules to be introduced gradually and for the transition to the new regime to be completed by 1 January 2019; rules on deductions from capital will be enacted in stages, becoming fully enforceable only in 2018. With reference to liquidity risk, the BCBS has proposed the introduction of two new and complementary indicators: the liquidity coverage ratio (LCR) and the net stable funding ratio (NSFR); the former would come into force at the beginning of 2015, the latter at the beginning of 2018.

A comprehensive and well-designed regulatory framework will make financial systems safer, but stability will require banks to hold extra capital and liquidity. The new requirements might make loans and other banking services more costly and harder to obtain, ${ }^{1}$ hampering economic activity in the short and mediumrun. However, the lower growth during non-crisis years may be more than offset by avoiding truly severe recessions and by dampening business cycle fluctuations.

\footnotetext{
${ }^{1}$ This claim is not undisputed. Admati et al. (2010) contends that banks' funding costs do not increase when equity requirements are raised: setting capital standards higher than the levels currently proposed would mean large social benefits and minimal, if any, social costs.
} 
The Institute of International Finance (IIF) ${ }^{2}$ assessed that the adoption of Basel III would cost Europe and the United States 3 percentage points of GDP; the French banking association estimated a GDP loss twice that figure for the national economy. Less worrisome results have been obtained by the Macroeconomic Assessment Group (MAG), established in February 2010 by the chairs of the FSB and BCBS with the mandate to quantify the short- to medium-term macroeconomic effects of the reform, and by the Long-term Economic Impact (LEI) working group, created by the BCBS to assess the steady-state costs and benefits of the reform. In its final report, the MAG estimated that if the transition to the new regime were to be completed in eight years, annual GDP growth would fall in 2011-2018 by 0.03 percentage points for each percentage point increase in the capital requirements (see MAG, 2010b). ${ }^{3}$ The LEI working group found that a 1 percentage point increase in the capital ratio would cause a $0.09 \%$ permanent decline in the level of output relative to the baseline. The benefits of the reform would mainly accrue in the form of a reduction in the probability of systemic banking crises. The estimates of the net benefits are highly uncertain, and crucially depend on assumptions about whether financial crises have permanent or transitory effects on the level and growth rate of real activity. The report concluded that the net benefits would be positive even in the case of a very substantial increase in capital requirements (see BCBS, 2010a).

This paper presents and expands on the work conducted by the Bank of Italy within the MAG and LEI working group. The objective is to provide an assessment of the costs - both during the transition period and in the long-run - of the proposed regulatory reform for the Italian economy. Consistently with the analysis underlying the MAG interim and final reports, we focus exclusively on capital and liquidity requirements, abstracting from the other measures that are contained in the package elaborated by the BCBS. The benefits associated with a stronger banking sector are not considered.

The paper is organised as follows: the next section reports on the experiments used to measure (in terms of GDP losses) the costs of imposing stricter constraints on banks' operations; Section 3 describes how the capital ratio, which typically does not enter econometric models, influences credit availability and bank lending rates, which are instead usually included; Section 4 provides a short description of the models used in the assessment of the links between prudential rules and economic outcomes; the following two sections explain how the banks' response to the regime change is transmitted to the economy in the transition phase (Section 5) and in the long run (Section 6); and Section 7 concludes.

\section{Higher capital and liquidity requirements: design of the experiments}

The September 2010 reform package prepared by the Governors and Heads of Supervision sets out the main pillars of the forthcoming Basel III framework and in particular the new capital requirements. The impact of the reform on each country's banking system and on the real economy depends on how far current capital

\footnotetext{
${ }^{2}$ The IIF includes among its members most of the world's largest commercial and investment banks, as well as a growing number of insurance companies and investment management firms.

${ }^{3}$ See the top-right panel of Graph 2. This number refers to the unweighted median of the responses estimated by 12 standards-based models.
} 
and liquidity conditions are from the target requirements. ${ }^{4}$ The maintained hypothesis underlying the experiments described in this paper is that the effects on the economy of higher capital ratios are essentially linear, so that the impact of an $x$ percentage point capital deficit is equal to $x$ times the impact of a 1 percentage point gap. ${ }^{5}$

Concerning the definition of regulatory capital, most existing regulatory regimes, as well as most available data on bank capitalisation, refer to broad definitions such as Tier 1 or Total Capital. However, during and after the financial crisis, market participants and the banks themselves increasingly focused attention on narrower concepts such as tangible common equity (TCE). Thus, the MAG and LEI group decided to frame the scenarios for capital in terms of the target ratio of TCE to risk-weighted assets (RWA), where RWA are based on definitions under Basel II. No distinction was made between the minimum capital requirement and additional buffers.

Under Basel III, banks will also be required to meet two new liquidity standards: a short-term requirement called the Liquidity Coverage Ratio (LCR) and a long-term requirement called the Net Stable Funding Ratio (NSFR). The LCR ensures that banks have adequate liquidity to survive one month of stressed funding conditions; the NSFR addresses the mismatch between the maturity of a bank's assets and that of its liabilities. After an observation period beginning in 2011, to be used as a safeguard against unintended consequences, the LCR will be introduced on 1 January 2015 and the NSFR will be enforced by 1 January 2018.

The design of the experiments for assessing the cost of enforcing the new liquidity standards is based on assumptions also adopted in MAG (2010a) and BCBS (2010a).

Some uncertainty is related to the timing of the transition to the new framework. The date by which banks have to fully comply with the new regulatory regime is 1 January 2019: the implementation period is long, but banks might try to achieve the capital target more quickly, either voluntarily or because forced to do so by the financial markets. Accordingly, the case of an anticipated adjustment to Basel III (to be completed by 2012 Q4) was also considered. Another relevant issue is the connectedness between liquidity and capital standards. When a bank changes the composition of its balance sheet to meet either the NSFR or the LCR, it increases its holdings of high-quality assets, lowering its RWA; this reduces the capital that must be held to satisfy the capital requirements. The interaction between the liquidity standards and the capital rules has been explicitly taken into account only when assessing the long-run costs.

Model simulations were run for twelve years (from 2011 Q1 to 2022 Q4), assuming that the capital requirements increase linearly during the implementation horizon (i.e. in 2011-2018 for the benchmark scenario and in 2011-2012 when banks frontload the adjustment). The experiments aimed at assessing the impact of the new liquidity standards were designed in a similar way.

\footnotetext{
${ }^{4}$ The impact of the reform on each country's banking system is analysed by the BCBS's Quantitative Impact Study (BCBS, 2010b), whose findings were made public on 16 December 2010.

${ }^{5}$ The same assumption, that is consistent with empirical evidence, was adopted also by the MAG and the LEI working group.
} 
All simulations were run keeping exchange rates constant at the baseline value. This assumption is justified on the grounds that the increase in bank lending spreads and in asset returns is not just a domestic occurrence, but rather takes place in most of the world economies, so that there is no reason to expect either an appreciation or a depreciation of any one currency. Quantity constraints on loan availability, unlike the widening of lending spreads, disappear immediately after the end of the implementation horizon; this assumption is equivalent to positing that credit rationing is a disequilibrium outcome and vanishes as soon as the new regime comes into force. Finally, following the methodology adopted in the MAG reports, simulations were run under two different monetary policy settings: in the first (passive monetary policy), the short-term nominal interest rate was kept at the same level as in the baseline; in the second (active monetary policy), the monetary stance was allowed to respond to the slowdown in economic activity and the decline of inflation. International spillovers were not considered. ${ }^{6}$

\section{From capital and liquidity ratios to interest rate spreads and credit availability}

Banks operate in a highly-leveraged fashion, in spite of the risks that an unbalanced financial structure poses, because capital is expensive, carrying more risks for investors than debt securities or deposits. As neatly explained in Kashyap et al. (2010), equity finance involves two different types of costs, namely flow and stock costs. The former are charges that banks bear when they have to raise new equity to reduce leverage; the latter are related to factors that make capital expensive to a bank on an ongoing basis, regardless of how equity comes to be on the balance sheet, whether by retaining earnings or by issuing capital to investors. The former are mostly short to medium-run costs; the latter are permanent.

Myers and Majluf (1984) provide the theoretical justification for the existence of flow costs of equity finance. When managers, supposed to act on behalf of shareholders, are better informed than outside investors, the decision to raise new equity is taken as a negative signal by investors, since managers are expected to raise new equity when they think it is overvalued as opposed to undervalued. Capital markets therefore ask for a price discount when a corporation issues new equity and in so doing encourage managers to opt for a highly leveraged capital structure: they prefer to use internal finance to finance investment plans and when initial equity and retained earnings are insufficient, they first issue debt, then hybrid securities and finally, as a last resort, equity. ${ }^{7}$ Managers can even decide to give up profitable projects if they cannot be financed without raising new equity. As stressed by Kashyap et al., the Myers-Majluf model offers an additional insight, with important policy implications: an overly-rapid phase-in of a higher capital standard may be responsible for subdued loan growth and increasing financing costs, while a gradual implementation of the new framework is likely to have a limited impact.

Violations of the Modigliani-Miller (1958) theorem are also a source of balance-sheet costs of equity finance. First and foremost, corporate income taxation favours debt, which is tax-deductible, over dividend

\footnotetext{
${ }^{6}$ The additional fall in GDP resulting from the simultaneous strengthening of capital adequacy standards across countries was estimated by the MAG (see MAG, 2010b) and found to be negligible ( $0.02 \%$ after 35 quarters) .

${ }^{7}$ This is the Myers and Majluf pecking order hypothesis. It captures the idea that neither internal finance nor defaultfree debt suffers from the informational asymmetries traditionally associated with external finance and are accordingly a cheaper source of funding.
} 
payments, which are not. Second, debt, and in particular short-term debt, protects shareholders from agency problems on the part of their management: debt, because of the looming threat of a run, disciplines managers and prevents them from taking risks that are not in the interests of shareholders.

Unlike flow costs, empirical evidence suggests that the balance-sheet costs of equity finance are negligible. Accordingly, while transition costs to stronger capital requirements may be significant, steady-state effects should be fairly small.

How do banks respond when regulators raise capital standards and force them to bear the costs that equity finance involve? Do they adjust the price of credit, its availability or both? How does a tightening of credit market conditions affect aggregate supply and demand? Identification problems and lack of empirical evidence make it difficult to answer any of these questions.

Save lending interest rates, econometric models scarcely ever include banking variables. In normal times, when markets work smoothly, banks and other intermediaries can be safely ignored and financing costs can be modelled through arbitrage equations, with the monetary policy instruments acting as the pivot of the whole spectrum of interest rates. If convenient, credit aggregates, interpreted as demand functions, can be added as post-recursive equations, which leaves the core properties of the model unaffected; no role at all is usually attached to other items in the profit-and-loss or balance-sheet statements of the banking sector. The main implication of this modelling framework is that bank capital, not to mention liquidity, does not enter econometric models, which are therefore unfit to assess the impact on the economy of regulatory reforms.

To overcome this problem, a two-step approach was adopted: first the Basel III reform agenda was mapped into changes in bank lending spreads and loan volumes; then the tightening of credit market conditions was translated into changes in household's and firm's spending and output. ${ }^{8}$ As there is no single well-established way to estimate the elasticity of the price and supply of credit to changes in capital (and liquidity) requirements, for the sake of robustness six alternative satellite models - ranging from DSGE to reducedform single-equation models - were used. In all but one case, the transition to the new regulatory regime was assumed to be gradual and to take place linearly. A short description of all the satellite models is provided in Appendix A.

Assembling the evidence that emerged from the previous models, one obtains the estimated path of lending spreads and volumes reported in Table 1. The median of the estimates was chosen as the most reliable measure of the cost of a 1 percentage point increase in the TCE-to-RWA ratio. Unfortunately, most of the satellite models were unable to provide a mapping between liquidity requirements and the price and the availability of credit; therefore, rather than computing in-house estimates, those elaborated by the MAG and the LEI working group were used. ${ }^{9}$ The MAG equates the increase in liquidity standards under Basel III to a $25 \%$ increase in the holding of liquid assets (combined with an extension of the maturity of banks' wholesale liabilities) and finds that, in order to achieve such a reshuffling of the asset side of the balance-sheet, lending spreads have to increase by $14 \mathrm{bp}$; the LEI working group associates the achievement of the NSFR target

\footnotetext{
${ }^{8}$ The procedures described in this section were agreed within the MAG and the LEI working group. See BCBS (2010a) and MAG (2010a).

${ }^{9}$ The estimates of the MAG and LEI working group were used only for lending spreads.
} 
with a rise in the cost of bank loans of 25 basis points (14 basis points when the interactions between liquidity and capital requirements are taken into account).

Table 1 - Response of spreads and volumes to a 1 percentage point increase in TCE/RWA

\begin{tabular}{|c|c|c|c|c|}
\hline \multirow{2}{*}{ Satellite Models } & \multicolumn{2}{|c|}{$\begin{array}{l}\text { Lending spreads } \\
\text { (basis points) }\end{array}$} & \multicolumn{2}{|c|}{$\begin{array}{l}\text { Lending volume } \\
\text { (percentages) }\end{array}$} \\
\hline & $\begin{array}{l}\text { Maximum } \\
\text { response }\end{array}$ & $\begin{array}{l}\text { Year of maxium } \\
\text { response }\end{array}$ & $\begin{array}{l}\text { Maximum } \\
\text { response }\end{array}$ & $\begin{array}{c}\text { Year of maxium } \\
\text { response }\end{array}$ \\
\hline SM1 (Notarpietro, 2010) & 0.27 & 2018 & -0.69 & 2018 \\
\hline SM2 (Gerali et al ., 2010) & 0.31 & 2017 & -0.77 & 2018 \\
\hline SM3 (Albertazzi-Marchetti, 2010) & 0.00 & - & -0.80 & 2018 \\
\hline SM4 (Cecioni, 2010) & 0.03 & 2018 & -0.01 & 2018 \\
\hline SM5 (Accounting Method) & 0.11 & 2018 & -0.28 & 2018 \\
\hline SM6 (MAG median results) & 0.13 & 2018 & -1.70 & 2018 \\
\hline Mean & 0.14 & & -0.71 & \\
\hline Median & 0.12 & & -0.73 & \\
\hline
\end{tabular}

Note: The satellite models have the same labels as in the main text. For those models that do not provide estimates of the response of lending volumes, the numbers shown in the table are obtained by means of the credit-rationing block of the BIQM.

\section{The Bank of Italy Quarterly Model and its reduced-scale version}

The assessment of the costs associated with the transition to Basel III was made using the Bank of Italy Quarterly Model (BIQM); ${ }^{10}$ the estimate of the long-run impact of the new regulatory framework was conducted simulating the maquette, i.e. a reduced-size, steady-state consistent version of the BIQM.

The BIQM is a semi-structural large-scale econometric model, describing an economy that exhibits Keynesian features in the short run, when the level of economic activity is primarily determined by the behaviour of aggregate demand, and neo-classical properties in the long run, akin to Solow's model of exogenous growth. Italy is modelled as a small open economy. Along a steady-state growth path, the dynamics of the model stems solely from capital accumulation, productivity growth, foreign inflation and demographics; in the short run, a number of additional features matters, in particular economic policies, expectations errors, wage and price stickiness and the non-malleability of capital.

The BIQM models separately the public and the private sector and, within the latter, distinguishes among energy, agriculture and the (rest of the) business sector. As to the expectations formation mechanism, the BIQM makes extensive use of survey data.

All equations in the model are estimated by limited-information techniques, mostly ordinary least squares. A small set of parameters, in particular some of those related to the user cost of capital, are calibrated. The BIQM contains about 700 equations (of which about 80 are stochastic).

\footnotetext{
${ }^{10}$ The theoretical features and statistical properties of the Bank of Italy Quarterly Model are described in Busetti et al. (2005).
} 
In the deterministic steady-state equilibrium - i.e. when (i) no shocks affect the model; (ii) expectations are fulfilled; and (iii) all adjustment processes have come to an end - the BIQM describes a full-employment economy: output, labour and the capital stock are consistent with an aggregate production function, relative prices are constant and inflation equals the exogenous rate of growth of foreign prices. Money is neutral, though not super-neutral, and the model is borderline stable even when no feedback policy rules are used, thanks to the presence of endogenous stabilising mechanisms coming from non fully-indexed financial wealth and competitiveness.

The supply sector can be thought of as being composed by producers who are price-setters in output market and price-takers in factor markets. Each producer, being endowed with the same Cobb-Douglas constantreturns-to-scale technology, knows the minimum average cost of his competitors and fixes the level of the mark-up so as to keep potential entrants out of business. Firms decide in each period the cost-minimising factor mix and the level of activity is set to meet expected demand. Capital is non-malleable, so that the capital-labour ratio cannot be modified for previously installed machineries. Life-cycle consumers choose the desired addition to the real stock of wealth, which is then allocated among foreign assets, physical capital and government debt. As consumers compute their life-time resources without anticipating the need for the government to satisfy a long-run solvency condition, the stock of public debt is perceived to be part of total wealth and Ricardian equivalence does not hold. Banking services are treated in the same way as other goods or services, implying that credit intermediaries, which have monopolistic power and set the price of their products, are not distinguished from non-financial firms. ${ }^{11}$ The real exchange rate adjusts so as to balance supply and demand. Fiscal variables are either exogenous or linked to changes in nominal GDP.

The size and degree of detail of the BIQM are helpful in improving the accuracy of short- to medium-run forecasts and in answering day-to-day policy issues, but they obscure its theoretical underpinnings and delay, and possibly prevent, the convergence to a steady-state equilibrium growth path. ${ }^{12}$ The BIQM is therefore not the right tool when the concern is for the steady-state equilibrium outcomes; accordingly, the assessment of the long-term economic impact of stronger capital and liquidity requirements was conducted using the maquette of the BIQM. ${ }^{13}$ Besides its size, the maquette differs from the BIQM in two important respects: first, it assumes that agents learn adaptively and form expectations by means of recursive least squares, choosing from a fixed number of alternative models and picking out the one exhibiting the best forecasting performance; second, it includes monetary and fiscal policy rules, which ensure that the model indeed

\footnotetext{
${ }^{11}$ The working of the credit market in the BIQM, which is based on Rodano (2009), is presented in Appendix B. The block of the BIQM modelling disequilibrium in the loan market provides a "structural" way to estimate the non-spread effects spurred by a change in the regulatory framework. It offers a reasonable approach to analyse the macroeconomic consequences of credit rationing, if anything because it has theoretical appeal, but suffers from identification issues. Because it did not fit the protocol set by the MAG, it was not utilised in the coordinated experiments described in MAG (2010a); as the protocol was subsequently modified, the credit market block contributed to the results incorporated in MAG (2010b).

${ }_{12}$ The features of the BIQM that hinder the convergence to a steady-state growth path are: (i) the inclusion of deterministic trends; (ii) the presence of seasonal variables; (iii) the modelling of tax revenues on a cash basis; (iv) the absence of a sufficient number of policy rules.

${ }^{13}$ The standard procedure for deriving a structural-form maquette is described in Masson (1988). Locarno (2002) provides a short description of the maquette of the BIQM.
} 
converges to a steady-state equilibrium. ${ }^{14}$ Both features shape the dynamic properties of the maquette, but in principle play no role in selecting the long-run equilibrium growth path and do not bias the results of comparative statics exercises.

\section{Higher capital and liquidity requirements: transition costs}

Stricter supervisory rules affect the economy through higher costs of financing and reduced credit availability, dubbed for short spread and non-spread effects. Regarding the first, increased bank lending rates affect household and firm spending in the same way as monetary policy does, though possibly more quickly. ${ }^{15}$ The adjustment process induces modifications in the composition of private and public sector balance sheets, which in turn exert second round effects on interest rates, thus setting the stage for the response of aggregate demand and supply: the interaction between the real and the financial side of the economy continues until a new equilibrium is reached. Interest rates affect output through five transmission channels: (i) the cost-of-capital channel, that works through changes in the optimal capital-output ratio; (ii) the substitution-effect-in-consumption channel, involving the response to financing costs of the relative price of present as opposed to future consumption; (iii) the income and cash-flow channel, based on how interestrate flows affect disposable income and whose effects depend on the financial structure of the economy and on the relative propensity to spend of borrowers and lenders; (iv) the wealth channel, that takes into account how fluctuations in borrowing conditions affect the discounted value of future expected payoffs of physical and financial assets; and (v) the exchange rate channel, that measures how fluctuations in exchange rates triggered by the uncovered interest-rate parity condition - affect competitiveness, the price of imported goods, aggregate demand and inflation.

While bank lending rates affect aggregate demand in several ways, credit availability exerts a more direct but harder to measure - impact on economic activity. When loans are not supplied in the amount required to satisfy notional demand, households and firms are forced to reformulate their spending plans, pushing current consumption below its desired level and cutting back investment projects that are profitable. Credit rationing may end up transforming a temporary lack of liquidity into insolvency, boosting the default rate of non-financial firms, especially small ones without direct access to capital markets, that rely entirely on bank credit for their financial needs. While it takes time for interest rate changes to come to bear upon spending plans, credit rationing acts more swiftly. All in all, it is reasonable to expect that non-spread effects may be of the same order of magnitude as those triggered by an increase of financing costs, though the empirical evidence on this issue is quite scant.

\footnotetext{
${ }^{14}$ The share of agents selecting each forecasting model follows a law of motion that is a discrete-time version of the replicator dynamics used in evolutionary game theory, which postulates gradual movements from worse to better models. It thus contrasts with another important class of dynamic processes in game theory, best response dynamics, which involves instantaneous movement to best replies.

${ }^{15}$ The transmission mechanism works in three phases: first, a change in bank lending rates spills over to other segments of the capital market, affecting financial asset returns and exchange rates; then, the movements in financial prices interact with the spending behaviour of households and firms; finally, the change in output and unemployment gaps, driven by the response of consumption and investment, induces wages and prices to adjust. The process goes on until the equilibrium is restored.
} 
Figure 1 presents the impact on output of higher lending spreads; it shows the median GDP response (with active and passive monetary policy) and the bounds of the envelope of the output responses corresponding to the alternative spread paths estimated by the six satellite models. ${ }^{16}$ The simulation horizon extends over 12 years, covering not only the transition to Basel III, but also four additional years.

Figure 1 - Impact of a 1 percentage point increase in capital requirements, spread effects (percentage deviation from baseline)

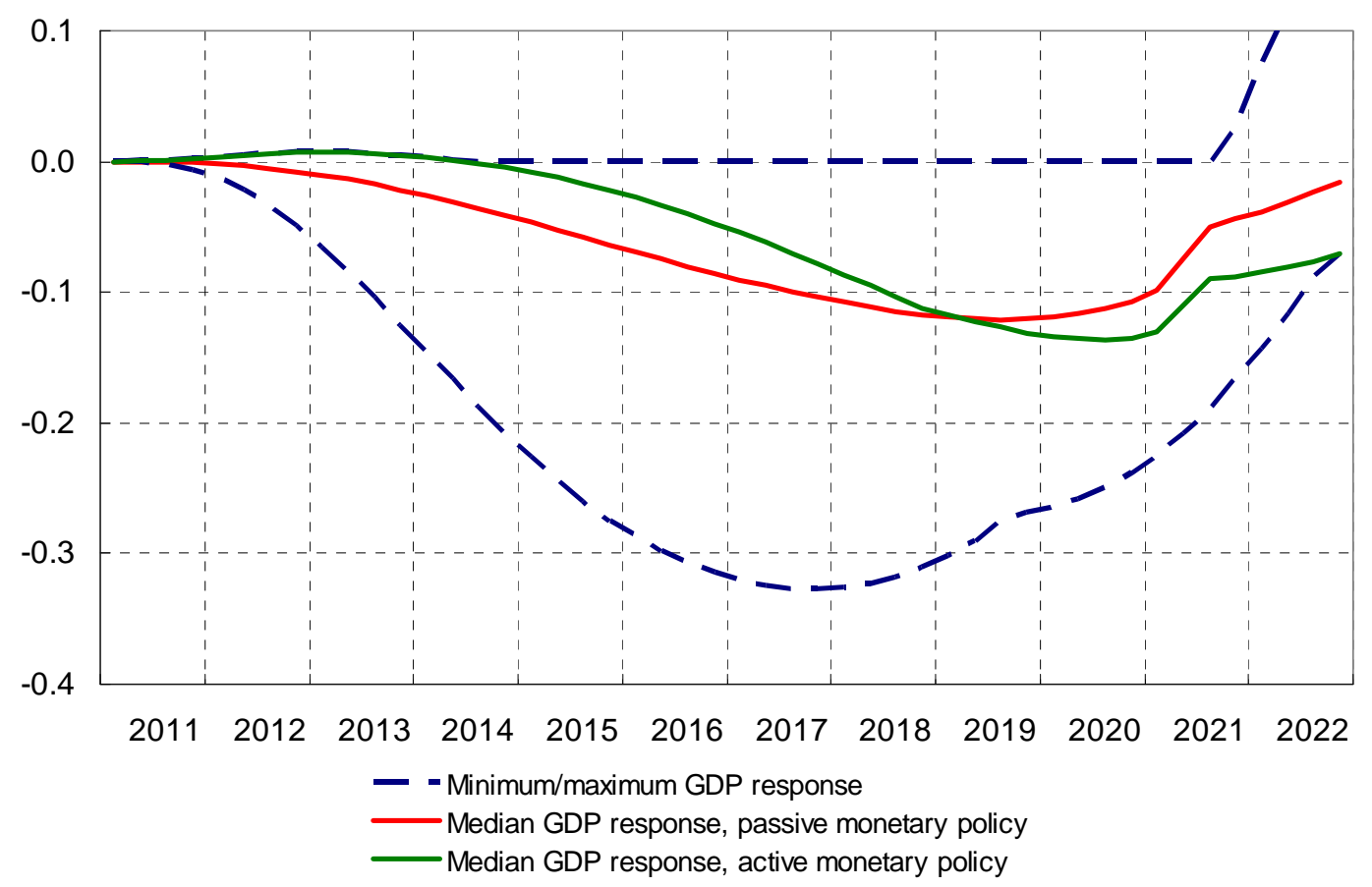

Note: the dashed-blue lines are the upper and lower bounds of the envelope of the output responses corresponding to the alternative spread paths estimated by the six satellite models

With passive monetary policy, the median response of output reaches a trough the year after the end of the transition period and then gradually recovers, as credit conditions stop deteriorating and borrowers adjust to the new, more restrictive, environment. The lower bound of the GDP response reverts to the baseline two years in advance, reflecting the frontloaded adjustment of bank lending spreads predicted by SM2 (the Gerali et al. model; see Appendix A). Output returns to baseline approximately at the end of 2022. The kink in 2021 reflects the non-linearity of the median operator: not all points of the curve belong to the same simulation, which may imply that at times sharp bends occur, even if all simulation responses are smooth. The GDP loss at trough ranges from $0 \%$ to $0.33 \%(0.12 \%$ in the median response with passive monetary policy), corresponding to a reduction of the growth rate of output in the transition period of at most 0.04 percentage points. Monetary policy can provide some relief at the beginning of the implementation period, but at the

\footnotetext{
${ }^{16}$ Unlike the mean, the median is not affected by extreme observations and is therefore a more robust statistic. It has however two unfortunate features, namely it is not additive (i.e. the median of the sum of a set of variables is not equal to the sum of the medians) and it does not preserve differentiability (i.e. the median of a set of continuous and differentiable functions in general has kinks). This is because the median is defined in terms of sup or inf functions, which are non-linear. The same properties - or lack thereof - apply to the upper and lower bound of the envelope curve.
} 
cost of deteriorating business cycle conditions in the years after the new regulatory framework has come into force.

The GDP loss becomes more substantial if higher capital requirements cause not only higher lending rates, but also restrictions in the supply of credit (i.e. credit rationing). Figure 2 presents the annual deviation of GDP from the baseline path and shows how much of it is due to spread effects, credit rationing and monetary policy. The output loss at trough ranges from $0.03 \%$ to $0.39 \%(0.23 \%$ in the median response with passive monetary policy), matching a weakening of economic growth in 2011-2018 of at most 0.05 percentage points. ${ }^{17}$

Figure 2 - Impact on GDP of a 1 percentage point increase in capital requirements (median responses; percentage deviation from baseline)

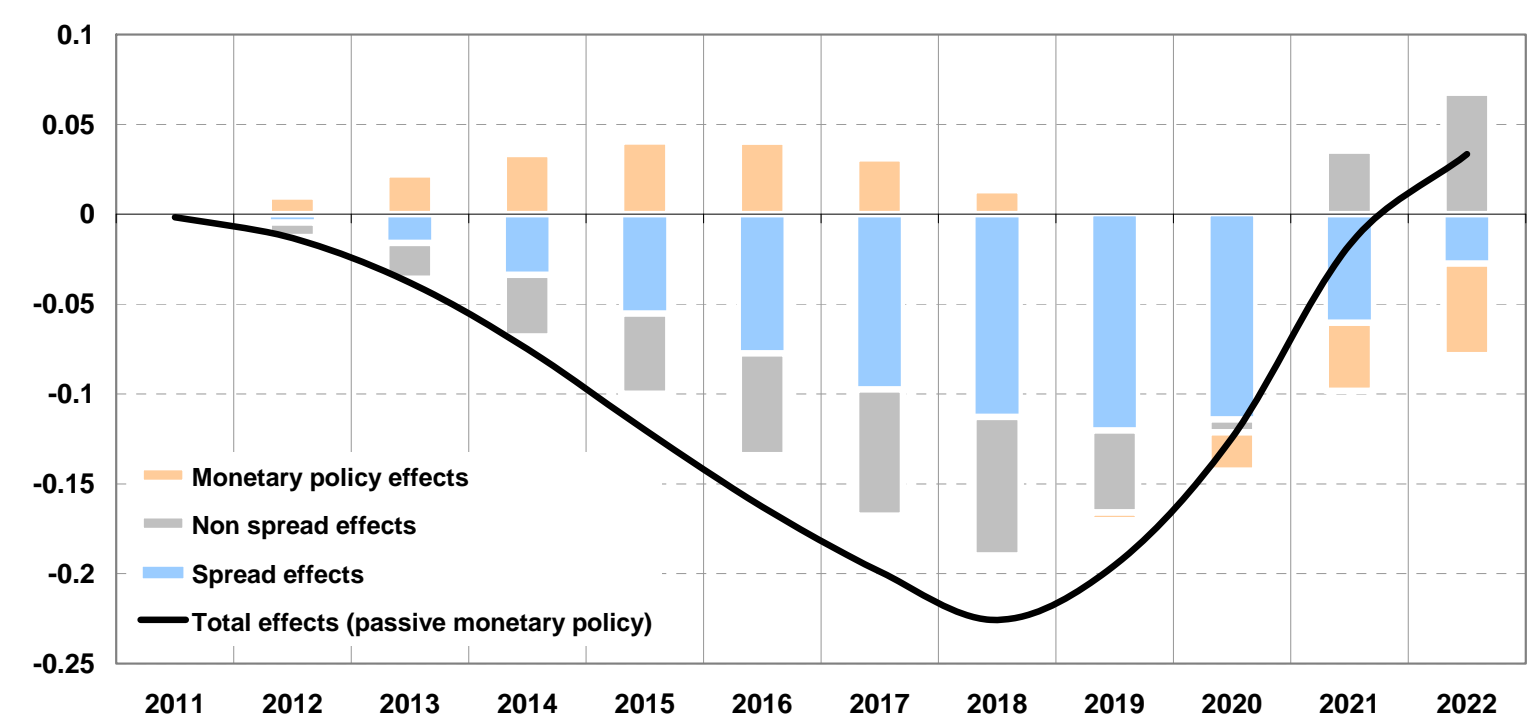

Note: spread and non-spread effects do not add up to the total, as the sum of the medians is not equal to the median of the sum. The black line (total effects) is the median of the sum of spread and non-spread effects, neglecting monetary policy.

Two results are worth stressing: (i) when credit supply restrictions are taken into account, the output loss clearly increases, although it remains modest; their effect is larger and faster than that of spread effects, and becomes positive in the final years, when the pent-up demand for credit is no longer constrained by supply restrictions; (ii) the contribution to GDP growth of monetary policy is modest and becomes negative after the end of the implementation horizon, when economic activity rebounds and the central bank needs to tighten conditions.

These results are very similar to those reported by MAG (2010b, graph 2). Based on the unweighted median response across 37 models, the MAG estimates that a 1 percentage point increase in the target capital ratio

\footnotetext{
${ }^{17}$ The GDP response shown in Figure 2 is more subdued than that included in the MAG Interim Report and mentioned in Carosio (2010) and Tarantola (2010). The difference is due to three factors: (1) the longer implementation horizon (8 years instead of 2 or 4); (2) the wider set of satellite models used to map capital requirements into changes in lending spreads and loan availability; (3) the change in the way non-spread effects are estimated. Other features of the results have instead remained almost unaltered, e.g. the fact that the trough is reached after the end of the transition period, the prompt reversion to the baseline after the end of the adjustment process and the greater impact on GDP of spread effects compared with credit rationing.
} 
causes a maximum GDP loss of $0.18 \%$ after 35 quarters; taking into account non-spread effects, which reduces to 12 the number of available models, the GDP loss reaches $0.21 \%$.

Figure 3 presents the contributions of capital accumulation and household spending to the fall in GDP. Investment is the component of aggregate demand which is most heavily affected by the worsening of financing conditions, while fluctuations in consumption are partly mitigated by the positive effect on disposable income and wealth resulting from the decrease in the price level. This outcome is not unexpected, since the contraction in capital accumulation reflects both the increase in the cost of borrowing and the drying up of funding sources. Credit rationing affects consumption much less heavily partly because of the sound financial position of Italian households and partly because of the low riskiness of mortgage lending. Abundant empirical evidence for Italy supports the BIQM specification that does not attach much relevance to liquidity constraints as a determinant of household spending decisions.

Figure 3 - Total impact of a 1 percentage point increase in capital requirements (median responses; percentage deviation from baseline; passive monetary policy)

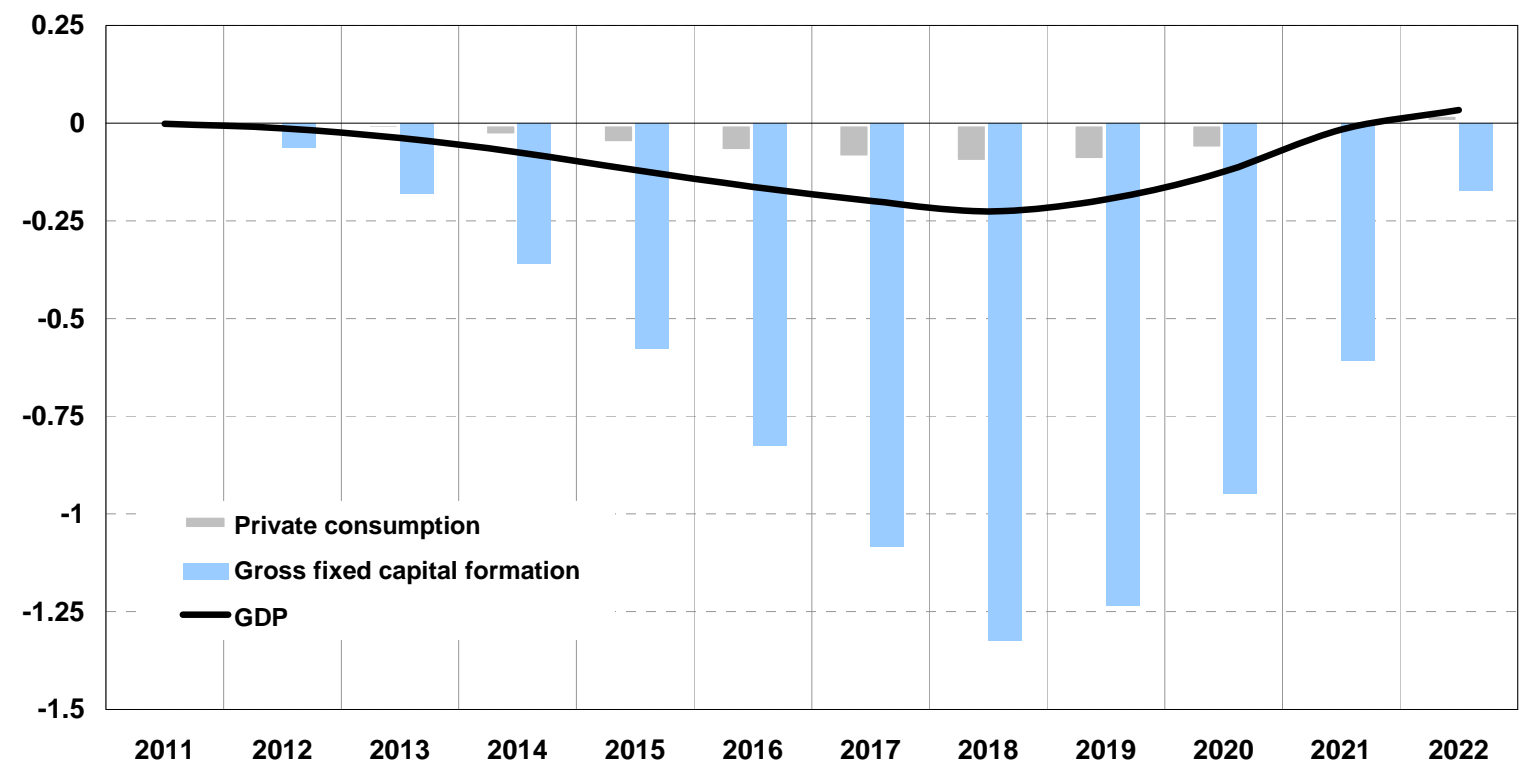

The size of the investment contraction is 5-6 times as big as the fall in GDP, while the drop in consumption is hardly half as much as that in output; the first result reflects both the higher interest-rate sensitivity of investments and the presence of a strong accelerator effect, while the more subdued response of household spending is consistent with consumption smoothing and with the stimulus provided by lower prices on the real value of wealth.

Net exports benefit from the contraction engendered by the initial shock and contribute to attenuating the slowdown in economic activity: imports fall substantially, dragged by the plunge in capital accumulation, the component of aggregated demand (together with merchandise exports) with the highest content of imported goods; exports hardly move, given the assumptions of unchanged world demand and exchange rates.

In the absence of a realignment of the domestic currency, the import deflator remains more or less constant as does the HICP on impact; as the output gap deteriorates, deflationary pressures show up and consumer 
prices start decreasing with respect to the baseline. This evidence is fully consistent with the price stickiness observed in oligopolistic markets and with capital being non-malleable: the first feature implies that changes in marginal costs are transmitted slowly to prices, as the mark-up cushions shocks to unit labour costs; the second characteristic justifies the smooth adjustment of labour demand and the limited response of wages and productivity to shifts in factor prices.

As the economy adjusts to the new prudential framework, so do banks' profits and net worth. The fall in output and the higher cost of credit drive down loans, especially those to non-financial corporations, and worsen interest-rate margins and profits. Bank capital declines, but less than total assets: under the assumption that the latter fall as much as loan volumes, the capital ratio increases ex-post as much as posited ex-ante.

In spite of the length of the transition period, banks might autonomously decide to speed up the shift to the new prudential regime. Banks might feel compelled to prove their capital soundness to the markets or might be afraid of being outsmarted by competitors. Were they to act so as to achieve the target capital ratios by the end of 2012, well ahead of the schedule set out by supervisors, output would reach a trough in the second half of 2014 and revert to baseline in 2019; taking into account both spread and non-spread effects, for each one percentage point of capital increase annual GDP growth would decrease by 0.02-0.14 percentage points in the period 2011-2013. The rebound in subsequent years documented in figure 2 would be correspondingly anticipated.

Given the structure of the BIQM, liquidity and capital requirements affect the economy through the same transmission channels. Simulation results based on the assumptions presented in Section 2 and 3, show that meeting the new liquidity targets causes an additional slowdown of annual output growth of at most 0.02 percentage points. The GDP loss is very close to that caused by the tightening of the capital standards, which is not surprising, as the widening of bank lending rates is nearly the same in both experiments. It is worth stressing that it is not correct to sum the costs of meeting the capital and liquidity requirements: when a bank raises its share of liquid assets, it increases its holding of high-quality investments, lowering its RWA and the equity needed to satisfy a given capital ratio. Accordingly, the GDP loss caused by the implementation of the new regulatory framework is likely to be less than the sum of the costs of meeting both the capital and the liquidity requirements.

\section{Higher capital and liquidity requirements: steady-state costs}

Focusing on the transition dynamics is fundamental in assessing the macroeconomic costs of regulatory reforms, but might offer a biased picture of the real burden of the regime change. First, the response of banks is not the same during and after the transition to the new regulatory framework: deleveraging and credit rationing shape the adjustment process, but disappear in the long run. Second, the economy needs time to settle at the new equilibrium and the initial costs of absorbing the policy shock are usually compensated, at least in part, by the buoyancy that follows the completion of the adjustment process. Twelve years are not a short forecast horizon, but they are not enough to fully incorporate the rebound that comes after the fall: a longer time perspective, even better an infinite horizon, is needed. Third, the flow costs (that arise when the 
leverage of a corporation is changed) and the stock costs (related to the advantages of debt finance over equity finance on an ongoing basis) of capital are of different sizes.

To assess the long-run impact of regulatory reforms, the maquette rather than the BIQM was used. ${ }^{18}$ To ensure the stability of the model, two feedback rules were included: (i) a Taylor rule, linking the short-term interest rate to the next-period expected inflation rate, the unemployment gap and the lagged interest-rate; (ii) a fiscal policy rule, setting the income and corporate tax rates as a function of the debt-to-GDP ratio and of labour market slack.

The results of the three postulated experiments are shown in Table 2. Two clarifications are necessary. First, when assessing the long-run costs of the regulatory tightening, only spread effects matter: rationing of the loan supply is a temporary phenomenon, occurring only in periods when the credit market is impaired and is unable to reach an equilibrium. Second, as for the assessment of the transition costs, the channels through which capital and liquidity requirements alter aggregate demand and supply are identical, as they affect the economy only by changing the cost of borrowing.

The GDP loss is driven for the most part by the cost-of-capital channel: the rise in interest rates induces a downward adjustment in firms' demand for capital, which causes a fall in the stock of productive capital and hence in output supply: increasing the target capital ratio by 1 percentage point causes a decline in steady state GDP of about $0.2 \%$. This effect is almost identical to the capital share multiplied by the fall in productive capital. The (real) exchange rate hardly changes and neither do relative prices; the trade balance improves slightly. The output contraction determines a shortfall in government revenues and a deterioration of public sector balances: the associated increase in the debt burden forces the government to raise taxes to keep the debt-to-GDP ratio at the target level. Thanks to the improvement of the primary surplus, the steadystate deficit-to-GDP ratio remains unchanged, notwithstanding the higher cost of borrowing. The composition of aggregate demand varies, though almost imperceptibly, with increases in the share of (net) exports and household spending matched by reductions in the fraction of output allocated to investments and government consumption. Households, being net lenders, benefit from higher financing costs: net capital income more than offsets the heavier tax burden. Changes in factor prices determine a shift in income distribution, to the disadvantage of workers.

Concerning liquidity, the estimated cost of meeting the NSFR is $0.21 \%$ of steady state GDP if the decline in RWA associated with the new liquidity requirements is taken into account (scenario L2); disregarding this interaction brings the estimate to $0.37 \%$ (scenario L1), arguably an upper bound for the effect.

\footnotetext{
${ }^{18}$ Two main approaches are available for evaluating the asymptotic properties of a dynamic non-linear model: the first the so-called direct approach - is based on the numerical solution of a static version of the model; the second - the indirect method - involves running a no-shock simulation for an extended period of time, until the model converges to the steady-state growth path. Each approach has its own merits and no one can be considered superior on a priori grounds: the direct approach, by getting rid of the dynamics of individual equations, increases the degree of interdependence among the endogenous variables and makes it harder to find a solution of the model; the indirect method, on the other hand, locates a long-run equilibrium whose features are not fully independent of the choice of the policy rules and the assumption about the expectations formation mechanism. On balance, the shortcomings of the direct approach seem more serious and accordingly we have opted for the indirect approach.
} 
The long-run GDP loss estimated for the Italian economy are on the high side of the estimates obtained for other economies considered in BCBS (2010a): the median output loss is about one half that estimated for Italy for capital requirements; the discrepancy is even larger for the liquidity targets. The difference is somewhat smaller if the comparison is restricted to the euro area. ${ }^{19}$

Table 2 - Steady-state impact of meeting the new capital and liquidity targets

\begin{tabular}{l|cccc} 
& Baseline & K1 & L1 & L2 \\
\hline output loss (\%) & 0.000 & -0.183 & -0.372 & -0.212 \\
consumption share & 0.641 & 0.641 & 0.641 & 0.641 \\
investment share & 0.203 & 0.202 & 0.202 & 0.202 \\
export share & 0.211 & 0.211 & 0.212 & 0.211 \\
import share & 0.203 & 0.203 & 0.203 & 0.203 \\
capital-output ratio & 3.493 & 3.475 & 3.456 & 3.472 \\
gov't deficit-to-GDP ratio & 0.024 & 0.024 & 0.024 & 0.024 \\
trade surplus to GDP ratio & -0.004 & -0.003 & -0.001 & -0.002 \\
income tax rate (\%) & 7.018 & 7.171 & 7.339 & 7.197 \\
relative consumer prices & 1.000 & 1.000 & 1.000 & 1.000 \\
labour share (\%) & 44.372 & 44.355 & 44.343 & 44.353 \\
real exchange rate (\%) & 1.000 & 0.999 & 0.999 & 0.999 \\
\hline
\end{tabular}

NB: The first column presents the steady-state value of the big ratios and of other key macroeconomic variables in the baseline scenario; the next columns report the values of the same variables in the three policy scenarios. The label K1 refers to the scenario assuming a 1\% increase of the target capital ratio. L1 and L2 indicate the experiments concerning the achievement of the liquidity requirements: L1 does not account for the synergies between the liquidity and capital objectives; L2 does. The labour share refers to employees only (i.e. selfemployed workers are excluded).

\section{Conclusions}

The core of the global financial reform agenda is focused primarily on capital and liquidity standards: on 12 September, the BCBS announced a substantial strengthening of existing rules. The minimum tangible common equity requirements will increase from $2 \%$ to $4.5 \%$; in addition, banks will be asked to hold a capital conservation buffer of $2.5 \%$ to withstand future periods of stress. The new liquidity standards will be focused on two indicators: the LCR, that imposes tighter controls on short-term liquidity flows, and the NSFR, that aims at reducing the maturity mismatch between assets and liabilities. Unfortunately, raising capital and liquidity standards may have a cost: banks may respond to regulatory tightening by passing on additional funding costs to their retail business, by raising lending rates - in order to keep the return on equity in line with market valuations - and/or by reducing the supply of credit - so as to lower the share of risky assets in their balance sheets. Reduced credit availability and higher financing costs could affect

\footnotetext{
19 Taken at face value, these differences are substantial; on statistical grounds, they are probably not. Given the difficulties of computing a rigorous measure of uncertainty, Angelini et al. (2011) consider the standard deviations of the point estimates computed using the cross-section of models analysed in BCBS (2010a). These statistics indicate that the uncertainty associated with the point estimates of the economic impact of the new capital and liquidity requirements are of the same order of magnitude as the estimated effects themselves. This suggests that more rigorous tests could fail to reject the hypothesis that the long-run effects of the new regulation are stronger in Italy than on average in the other countries surveyed in BCBS (2010a).
} 
household and firm spending. While the regulator has taken this concern into account, planning a long transition period (until 2018), the new rules could cause subdued GDP growth in the sort to medium term.

How large is the effect that the new rules are likely to have on GDP in Italy? Not very, according to the estimates presented in this paper. For each percentage point increase in the capital requirement, implemented over an eight-year horizon, the level of GDP relative to the baseline path would decline at trough by 0.00 $0.33 \%$, depending on the estimation method (0.03-0.39\% including non-spread effects); the median decline at trough would be $0.12 \%$ ( $0.23 \%$ including non-spread effects). The trough occurs shortly after the end of the transition period; thereafter, output slowly recovers and by the end of 2022 it is above the baseline value. Based on these estimates, the reduction of the annual growth rate of output in the transition period would be in a range of 0.00-0.04 percentage points (0.00-0.05 percentage points including non-spread effects). The fall in output is driven for the most part by the slowdown in capital accumulation, which suffers from higher borrowing costs (and credit supply restrictions). Compliance with the new liquidity standards also yields small costs. The additional slowdown in annual GDP growth is estimated to be at most 0.02 percentage points. These results are broadly similar to those shown in MAG (2010b), derived for the main G20 economies.

If banks felt forced by competitors or financial markets to speed up the transition to the new capital standards, the fall in output could be steeper and quicker. Assuming that the transition is completed by the beginning of 2013, GDP would reach a trough in the second half of 2014; for each percentage point increase in capital requirements, GDP would slow down by 0.02-0.14 percentage points in each year of the 20112013 period. It would subsequently rebound, partly compensating the previous fall.

Long-run costs of achieving a 1 percentage point increase in the target capital ratio are also small (slightly less than $0.2 \%$ of steady state GDP); those needed to comply with the new liquidity requirements are of similar size.

J.K. Galbraith once said that the only function of economic forecasting is to make astrology look respectable. Econometric estimates are typically subject to high uncertainty; those presented in this paper are no exception. The main finding of this paper is nonetheless shared by several other studies: the economic costs of stronger capital and liquidity requirements are not huge and become negligible if compared with the potential benefits that can be reaped from reducing the frequency of systemic crises and the amplitude of boom-bust cycles. BCBS (2010a) evaluates that if the capital ratio increases by 1 percentage point relative to the historical average, the expected net benefits in terms of GDP level would be in a range of $0.20-2.32 \%$, $(0.25-3.33 \%$ if liquidity requirements are also met) depending on whether financial crises are assumed to have a temporary or a permanent effect on output. Even taking the most cautious estimate, the gains undoubtedly outweigh the costs to be paid to achieve a sounder banking system. 


\section{References}

Admati, A.R., P.M. DeMarzo, M.F. Hellwig and P.C. Pfleiderer (2010): Fallacies, Irrelevant Facts, and Myths in the Discussion of Capital Regulation: Why Bank Equity is not Expensive, Rock Center for Corporate Governance at Stanford University, Working Paper No. 2010/42.

Albertazzi, U., and D.J. Marchetti (2010): Credit supply, flight to quality and evergreening: an analysis of bank-firm relationships after Lehman, Banca d'Italia, Working Paper (Temi di Discussione), No. 756.

Angelini, P., and L. Clerc, V. Cúrdia, L. Gambacorta, A. Gerali, A. Locarno, R. Motto, W. Roeger, S. Van den Heuvel and J. Vlček (2011): BASEL III: Long-term impact on economic performance and fluctuations, Bank for International Settlements, Working Paper, No. 338.

Barrell, R., E. Davis, T. Fic, D. Holland, S. Kirby and I. Liadze (2009): Optimal regulation of bank capital and liquidity: how to calibrate new international standards, UK Financial Services Authority, Occasional Paper Series, No. 38.

BCBS (Basel Committee on Banking Supervision) (2010a) (LEI Report): An Assessment of the Long-Term Impact of Stronger Capital and Liquidity Requirements, Basel.

BCBS (Basel Committee on Banking Supervision) (2010b): Results of the comprehensive quantitative impact study, Basel.

Busetti, F., A. Locarno and L. Monteforte (2005): The Bank of Italy's quarterly model, in "Econometric Models of the Euro-area Central Banks", edited by G. Fagan and J. Morgan, Edward Elgar Publishing.

Carosio, G. (2010): L'effetto delle regole di Basilea 3 sulla patrimonializzazione delle banche e sull'economia, Testimony to the Senate.

Cecioni, M. (2010): The effect of bank capital on economic activity: results from structural VAR and VECM, Banca d'Italia, mimeo.

Elliott, D. (2009): Quantifying the effects on lending of increased capital requirements, Pew Financial Reform Project Briefing Paper, No 7.

Fair, R.C. and D.M. Jaffee (1972): Methods of Estimation for Markets in Disequilibrium, Econometrica, vol. 40.

Francis W. and M. Osborne (2009): Bank regulation, capital and credit supply: Measuring the impact of prudential standards, UK Financial Services Authority, Occasional Paper Series No. 36.

Gambacorta, L. (2010): Do bank capital and liquidity affect real economic activity in the long-run? A VECM analysis for the U.S., BIS; mimeo.

Gerali, A., S. Neri, L. Sessa and F. Signoretti (2010), Credit and Banking in a DSGE Model, Journal of Money, Credit and Banking, vol. 42. 
Hanson, S., A. Kashyap and J. Stein (2011): A macroprudential approach to financial regulation, Journal of Economic Perspectives, vol. 25.

Institute of International Finance (2010): Interim report on the cumulative impact on the global economy of proposed changes in the banking regulatory framework.

Kashyap, A., J.C. Stein and S. Hanson (2010): An Analysis of the Impact of "Substantially Heightened" Capital Requirements on Large Financial Institutions, mimeo.

Locarno, A. (2002): The "core" of the Bank of Italy Quarterly Model, mimeo.

MAG (Macroeconomic Assessment Group) (2010a): Assessing the Macroeconomic Impact of the Transition to Stronger Capital and Liquidity Requirements, group established by the Financial Stability Board and the Basel Committee on Banking Supervision, August.

MAG (Macroeconomic Assessment Group) (2010b): Assessing the Macroeconomic Impact of the Transition to Stronger Capital and Liquidity Requirements - Final Report, group established by the Financial Stability Board and the Basel Committee on Banking Supervision, August.

Masson, P. (1988): Deriving Small Models from Large Models, in "Empirical Macroeconomics for Interdependent Economies", edited by G. Holtan et al., Brookings Institution Press.

Modigliani, F. and M.H. Miller (1958): The cost of capital, corporation finance and the theory of investment, American Economic Review, vol. 48.

Myers, S.C. and N. Majluf (1984): Corporate financing and investment decisions when firms have information that investors do not have, Journal of Financial Economics, vol. 13.

Rodano, M.L. (2009): Simulating the impact of credit restrictions on the Italian economy, mimeo.

Tarantola, A.M. (2010): La revisione delle regole prudenziali: i possibili effetti su banche e imprese, Testimony to the Chamber of Deputies. 


\section{Appendix A}

Six satellite models were used to map changes in capital requirements into changes in lending spreads and volumes. A short description follows.

SM1: Lending wedge equations (Barrel et al., 2009) - The approach uses banking-sector aggregate data to estimate equations for the spread between bank lending and borrowing rates. The presumption is that any regulation on banking activity must, to be effective, act as a tax on banks and hence lead to a widening of the spread between borrowing and lending rates. Indeed, empirical evidence confirms that if banks move below their normal precautionary level of excess capital, they appear to respond by increasing the cost of borrowing for firms and households in order to restore the desired amount of excess capital. ${ }^{20}$ In line with Barrell et al. and the MAG protocol, the following specification was used for Italian bank lending spreads:

$$
\Delta w_{t}=\mu+\sum_{k=1}^{p} \alpha_{k} \Delta w_{t-k}+\sum_{k=1}^{q} \beta_{k} \Delta z_{t-k}-\gamma\left(w_{t-1}-\eta\left(k_{t-1}-k_{t-1}^{*}\right)-\delta^{\prime} z_{t-1}\right)+\varepsilon_{t}
$$

where $w_{t}$ is the spread (on mortgages or loans to firms, for short or long-term credit), $k_{t}-k_{t}^{*}$ indicates excess capital and $z_{t}$ is a vector a control variables, whose elements measure essentially cyclical conditions or the balance-sheet position of the borrowers. In Barrel et al. (2009), non-linear effects of shortages of capital were caught by adding to the specification an indicator of the difference between actual and target risk-weighted capital; a similar approach on Italian data did not provide statistically significant results.

SM2: a DSGE model with financial intermediaries and bank capital (Gerali et al., 2010) - Gerali et al.'s model is similar in most respects to other current DSGE models. It assumes that the economy is populated by households and entrepreneurs: households consume, work and accumulate housing, while entrepreneurs produce a homogenous intermediate good combining capital bought from capital-good producers and labour supplied by households. Agents differ in their degree of impatience, i.e. in the discount factor they apply to the stream of future utility. One distinctive feature of the model is that it incorporates credit intermediaries and financial instruments. Two types of one-period financial instruments, supplied by banks, are available to agents: deposits and loans. The heterogeneity in agents' discount factors determines positive financial flows in equilibrium: patient households purchase bank deposits and do not borrow, while impatient consumers and entrepreneurs demand loans. Banks operate in a regime of monopolistic competition and set interest rates on deposits and loans in order to maximize profits. The quantity of loans issued by each intermediary can be financed through the amount of deposits they raise or through equity. Banks accumulate capital out of retained earnings, trying to maintain the ratio of capital $\left(K_{t}\right)$ to loans $\left(L_{t}\right)$ as close as possible to a "desired" level (v). Since banks face quadratic costs of deviating from the desired capital-to-asset ratio, loan rates $\left(R_{t}^{L}\right)$ are set as:

$$
R_{t}^{L}=\text { monetary policy } \quad \text { rate }-\kappa_{b}\left(\frac{K_{t}}{L_{t}}-v\right)\left(\frac{K_{t}}{L_{t}}\right)^{2}+\text { markup }
$$

\footnotetext{
${ }^{20}$ Section 2 of Barrel at al. (2009) presents evidence on the link between capital requirements and bank lending spreads.
} 
Lending rates reflect supply-side factors; the demand for loans depends on investment opportunities.

Capital requirements are modelled as an exogenous increase in the parameter $v$ : an upward adjustment in $v$ triggers a rise in the cost of borrowing and a fall in the volume of credit. Even assuming a linear increase of capital requirements, the change in bank lending spreads is not uniform throughout the implementation period, which distinguishes this approach from all the others. ${ }^{21}$

When used for assessing the macroeconomic impact of the new regulatory regime, the model was calibrated on Italian data, while euro-area information was used for estimating the response of monetary policy.

SM3: The Albertazzi-Marchetti model (2010) - The model, which uses highly detailed data on bank-firm relationships in Italy, is developed to find evidence of a capital-related contraction of credit supply and to assess whether rationing is across-the-board or targeted to high-risk borrowers. Lending to a given firm may diminish not only out of a desire to maintain an adequate level of capital - be it connected with prudential regulation or market discipline - but also because of a perceived increase in applicants' risk, which requires controlling for borrower-specific factors. One of the main objectives of the paper is to investigate if capitalrelated contractions of credit supply have a diversified impact across firms, either because the risksensitivity of prudential regulation may induce a bias towards riskier borrowers or because less-capitalized banks may roll over loans to high-risk firms, in order to delay the recognition of losses (called "evergreening" or "zombie lending").

The mapping between capital and bank lending represents the first step of the empirical analysis and involves estimating the following equation:

$$
\Delta l_{b, i}=\alpha+\beta k_{b}^{\text {low }}+\gamma^{\prime} d_{i}+\eta_{i}+u_{i, b}
$$

where $\Delta l_{b, i}$ is the change in outstanding loans extended by bank $b$ to firm $i$, divided by firm $i$ 's total assets; $k_{b}^{\text {low }}$ is a dummy for low-capitalized banks (i.e., banks whose capital ratio is lower than 10 per cent, the level recommended by the Bank of Italy); $d_{i}$ is a vector of additional bank characteristics (such as liquidity and size) and $\eta_{i}$ is a firm-specific fixed-effect, that allows the authors to control for firm's credit demand as well as any other firm's characteristic. To estimate the impact of Basel III, the above equation was re-estimated using as a regressor the capital gap instead of $k_{b}^{\text {low }}$; a similar specification, with bank lending interest rates as endogenous variables, was used to measure the impact of the stronger capital requirements on the price of credit. Econometric evidence suggests that $\beta$ is negative and statistically significant for the loan equation, while bank capital seems to have no effect on lending rates.

SM4: a 6-variable VECM (Cecioni,2010) - Following the approach used by Gambacorta (2010) on U.S. data, Cecioni estimates a VECM on a small set of macro and credit variables, aiming at identifying the demand and supply of bank loans. The variables included in the VECM are the log of real GDP (Y), the real short-term interest rate $(r-\pi)$, the spread between the average lending rate and the money market rate $(i-r)$, the $\log$ of real loan volumes $(L)$, the $\log$ of the liquidity ratio of banks $(L I Q)$ and the log of the capital-to-asset

\footnotetext{
${ }^{21}$ In all the simulations run with SM2, the maximum increase in the cost of credit was reached in 2017, a few quarters before the end of the implementation period.
} 
ratio $(C A P)$, measured by the ratio between Tier 1 capital and risk-weighted assets. Data supports the existence of two cointegrating relationships, representing credit demand (in log-linear form) and bank lending spreads, interpreted as an inverted loan supply function. The estimated long-run relationships, with standard errors in brackets, are the following

$$
\begin{aligned}
L= & 1.229 Y-0.273(i-r) \\
& (0.015) \quad(0.049) \\
i-r= & 2.573 \mathrm{LIQ}+3.023 \mathrm{CAP} \\
& (0.679)
\end{aligned}
$$

According to the estimates, a 1 percentage point increase in the capital-to-asset ratio raises the spread between the average lending rate and the money market rate by 3 basis points and lowers loan supply by $0.01 \%$.

SM5: Accounting-based approach ${ }^{22}$ - The starting point of (a highly simplified version of) the method is to consider a stylised bank, whose balance-sheet composition coincides with that of the banking sector in a "normal" year. Let's assume that loans account for a fraction $\alpha$ of total assets and that raising equity capital costs $10 \%$ more than collecting deposits. A 1 percentage point rise in the capital-to-asset ratio implies higher funding costs (by $10 \mathrm{bps}$ ), lower profits and a decline in the return on equity. Keeping unchanged the size and the composition of banks' assets, an increase in the capital ratio of 1 percentage point requires a step-up of lending rates equal to $10 \mathrm{bps}$ divided by $\alpha$, in order to preserve the pre-reform level of profitability. ${ }^{23}$ It is worth stressing that the accounting-based approach provides estimates that measure the long-run impact of changes in the capital-to-asset ratio, but it is silent on how bank lending spreads behave along the transition path from one equilibrium to the other; moreover, it assumes that banks respond to the new regulatory framework by raising the cost of credit without reducing its availability.

SM6: Cross-country results of the MAG and LEI working group - To measure the response of banks to the shift in the regulatory framework, the evidence gathered by the MAG and LEI working group was also taken on board. This choice increases the robustness of the econometric findings, by widening the set of satellite models employed. ${ }^{24}$ Concerning bank lending rates, BCBS (2010a) measures a median response of 13 bps to a 1 percentage point increase of the TCE/RWA ratio; regarding lending volumes, MAG (2010a) estimates that a $1.4-1.9 \%$ reduction takes place during the transition to the new regulatory framework: ${ }^{25}$ the midpoint of this interval - rounded up to the upper decimal - was used in the experiments described in the paper.

\footnotetext{
${ }^{22}$ An example of this approach is presented in Elliott (2009).

${ }^{23}$ Besides assuming that banks pass on any additional costs to lending spreads and do not adjust other sources of income or operative expenses, the accounting approach takes it for granted that the return on equity and the cost of debt do not change with lower leverage.

${ }^{24}$ According to MAG (2010a), lending spread effects were estimated using 14 different models and credit rationing using just 9.

${ }^{25}$ According to the evidence shown in Table 1 of MAG (2010a), the median response of lending volumes to a 1 percentage point increase of the capital target does not depend on the implementation horizon.
} 


\section{Appendix B}

The working of the credit market is summarised by quantity equations, which are assumed to represent demand, and price equations, which describe how the pricing strategies of financial intermediaries react to cyclical fluctuations and monetary policy impulses. The BIQM includes equations for short and long-term bank interest rates, for loans to firms and mortgages and allows for the possibility of persistent imbalances between supply and demand for bank loans (i.e. credit rationing). Credit rationing is modelled by means of a framework developed for estimating the demand and supply curves for a market that is in disequilibrium. ${ }^{26}$

Figure 1B - Supply-constrained equilibrium

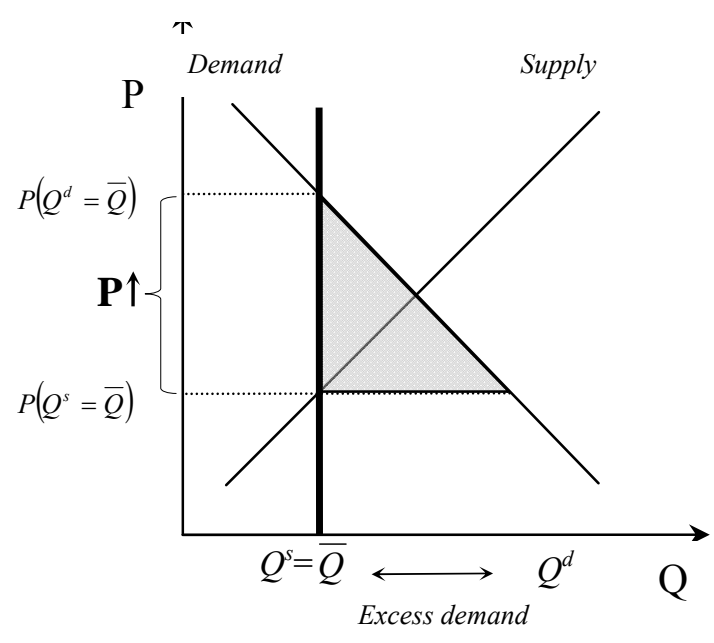
Occasionally the notional (unobserved) demand for a good (or service) may exceed supply, so that part of it goes unsatisfied; when the market is characterized by excess demand, the (relative) price of the rationed product lays between the demand and supply schedules and shows a tendency to rise (see Figure 1B). The (relative) price change may thus be used as an indicator of excess demand:

$$
\Delta \mathrm{P}_{\mathrm{t}}=\gamma \cdot\left(\frac{\mathrm{Q}^{\mathrm{d}}{ }_{\mathrm{t}}-\mathrm{Q}^{\mathrm{s}}{ }_{\mathrm{t}}}{\mathrm{Q}_{\mathrm{t}-1}^{\mathrm{s}}}\right) \text { with } \gamma>0
$$

If excess demand is small, prices settle on a level just above the equilibrium level and quantities only marginally fall off the demand schedule.

In the credit market, the (relative) price is defined as the difference between the interest rate on (short-term) loans and the overnight interest rate, so that the following relationship is postulated:

$$
\Delta r_{t}=\gamma \cdot \frac{C R_{t}}{\bar{L}_{t-1}}=\gamma \cdot \frac{L_{t}^{d}-\bar{L}_{t}}{\bar{L}_{t-1}} \text { with } \gamma>0
$$

$\Delta \mathrm{r}_{\mathrm{t}}$ is the change in the interest rate spread, ${ }^{27} C R_{t}$ is credit rationing, $L_{t}{ }^{d}$ is the notional demand of loans and $\bar{L}_{\mathrm{t}}$ are observed loans. Credit rationing thus is a function of observables and of the unknown parameter $\gamma$.

\footnotetext{
${ }^{26}$ The modelling of credit rationing is based on Fair and Jaffee (1972).

${ }^{27}$ In the BIQM specification, the relative price of credit is defined not as the current, but as the $4^{\text {th }}$-order moving average of the difference between the interest rate on short-term loans and the overnight interest rate. Accordingly occasional rises in the spread do not necessarily signal rationing in the credit market; the latter phenomenon is instead associated with persistent increases in the (relative) cost of bank credit.
} 
In order to identify and measure the amount of excess demand, a model for the supply of credit ( $\left.\bar{L}_{t}\right)$ is needed. In normal times, loan provision equals demand and both correspond to the market-clearing volume of actual lending; when credit rationing occurs, actual loans equal the difference between the notional demand of loans $L_{t}^{d}($.$) and the amount that goes unsatisfied. Thus the following expression can be given to$ the data:

$$
\bar{L}_{t}=L_{t}^{d}(\cdot)-C R_{t}=L_{t}^{d}(\cdot)-D_{t}\left(\frac{1}{\gamma} \Delta r_{t}\right) \cdot \bar{L}_{t-1}
$$

$D_{t}$ is a dummy variable that equals zero when the credit market is in equilibrium; it takes values greater than zero whenever the amount of available credit is somehow constrained and cannot meet demand. Factual information on the dummy variable is not available; to circumvent this problem, it is assumed that the presence of a disequilibrium is signaled by the Bank Lending Survey (BLS) indicator on credit standards, whose time-series starts in 2003 Q1.

Though gauging the size of loan market imbalances is interesting as such, in the BIQM an estimate of $C R_{t}$ is instrumental in appraising the impact of the credit squeeze on equipment investment, ${ }^{28}$ which is the component of aggregate demand most severely affected. Accordingly, the investment equation is modified to include the estimate of credit rationing among the regressors:

$$
I_{t}=I_{t}^{d}(\cdot)-\alpha \cdot C R_{t} \quad \text { with } \quad C R_{t}=D_{t} \cdot\left(\frac{1}{\gamma} \Delta r_{t}\right) \cdot \bar{L}_{t-1}
$$

where $I_{t}$ is equipment investment in time $t$ and $I_{t}^{d}(\cdot)$ is the specification of the investment equation when credit markets work smoothly.

\footnotetext{
${ }^{28}$ Econometric analysis provides no evidence that consumer spending is sensitive to credit market conditions.
} 